\title{
WASHINGTON BENAVIDES
}

\section{WASHINGTON BENAVIDES, UM AMIGO DA LITERATURA BRASILEIRA}

Entre os países hispânicos, o Uruguai é um dos mais próximos da cultura brasileira. Não por acaso, foi ali que se editou a primeira tradução de um livro de Machado no exterior: Memorias póstumas de Blas Cubas, feita por Julio Piquet e publicada em 1902. E entre os escritores uruguaios, um dos mais próximos da cultura brasileira é Washington Benavides, poeta, letrista, crítico e tradutor. Nascido em Tacuarembó em 1930, Benavides foi professor de literatura em sua cidade natal e depois na Facultad de Humanidades da Universidad de la República, em Montevidéu. A obra poética de Benavides é extensa e variada. Seu livro de estreia foi Tata Viscacha, em 1955, mas antes dessa data já chamava a atenção da crítica por seus poemas publicados em revistas. Entre seus livros de poemas, cabe destacar Las milongas (1965), Hokusai (1975), Los pies clavados (2000) e Amarili y otros poemas, de Pedro Agudo (2007). Desde o início, a crítica detectou uma voz complexa, síntese de seu amplo leque de leituras e interesses. Em seus sucessivos livros, Benavides combina recursos da lírica popular e culta, nacional e internacional, hispânica e de outros idiomas, contemporânea e dos séculos passados. Assim, convivem em sua poética a tradição hispânica, a poesia trovadoresca provençal e galaico-portuguesa, a poesia clássica oriental e ocidental e a moderna poesia de língua inglesa, com destaque para Ezra Pound. Uma faceta particular de Benavides é sua inserção no cancioneiro uruguaio, seus versos tento sido mu- 
sicados por compositores como Daniel Viglietti, Eduardo Darnauchans, Alfredo Zitarrosa e Héctor Numa Moraes. Benavides fez também incursões na ficção e escreveu prólogos para dezenas de obras das Ediciones de la Banda Oriental. Durante toda sua carreira, Benavides manterá contato constante com a literatura brasileira, traduzindo alguns de seus principais escritores, com ênfase na poesia e na prosa criativa. Em pequenos livros, publicados regularmente ao longo de décadas, Washington Benavides foi pioneiro da tradução no Uruguai e no âmbito hispânico, entre outros, de textos de Gregório de Matos, Oswald de Andrade, Guimarães Rosa, Clarice Lispector e Haroldo de Campos.

Rosario Lázaro Igoa \& Walter Carlos Costa

UFSC

Cadernos de Tradução (CT): ¿Cómo se interesó por el portugués? ¿De qué forma fue el inicio de este contacto de tantas décadas con la lengua de los vecinos?

Washington Benavides (WB): El punto de partida es que yo nací en un departamento del Noreste del Uruguay, en Tacuarembó, donde, en menor medida que en los países limítrofes, hay una influencia notoria de Brasil, y principalmente de Rio Grande. Además, mi padre, Héctor Benavídez, había nacido en Rivera. Para mí el conocimiento oral y auditivo del portugués, así como de la zona intermedia del dialecto fronterizo del portuñol o carimbão, fue algo tan natural como el español. Por lo tanto, hay tres posibilidades lingüísticas que me acompañaron desde la infancia. Por ejemplo, cuando de niño mi padre me contaba muchas veces historias, las mismas eran de origen brasileño. Había un héroe que era una especie de Mowgli de Rudyard Kipling, un niño salvaje de nombre "Tiririca". 
CT: ¿Quiénes fueron los primeros autores brasileños con los que tuvo contacto?

WB: Yo ya tenía contacto con lo galaico-portugués de los cancioneros por un lado, con Rosalía de Castro en los que hice los primeros intentos de traducción. Por otra parte, mis primeras lecturas fueron de los libros que aparecían en el Río de la Plata, como Monteiro Lobato, y después el reinado de Jorge Amado, a quien la Editorial Losada le fue publicando todos los títulos. Además, acostumbraba a hacer incursiones en las ciudades de la frontera, o hasta ciudades más adentro, como Bagé, Pelotas, Porto Alegre, buscando libros. Sumado a lo anterior, debido a mi asma de niño, fui un lector desaforado y precoz que a los seis años ya había leído los clásicos. Las clases de escuela fueron un tormento, con aquellas cosas de "Mi mamá me mima", que eran muy aburridas después de haber leído a Cervantes. En aquel momento, Arístides Mancilla y Molina, director de la escuela de curioso nombre, se dio cuenta de que yo era un "alien" y me puso a cargo de la biblioteca.

CT: ¿Cómo se inició usted en la docencia?

WB: Estuve ligado a Magisterio, y antes de profesor en Secundaria, fui profesor de Historia del Arte, pues dibujaba y pintaba como hoy lo sigo haciendo. Antes que la palabra, me fascinaba el dibujo y el color. Al mismo tiempo, escribía y mi primer libro, Tata Vizcacha (1955), fue quemado acusado de subversivo en la plaza de Tacuarembó. Más adelante, por concurso entré como profesor de Literatura en Paso de los Toros, donde estuve hasta 1960, y cuando falleció mi padre conseguí un traslado para el Liceo de Tacuarembó. Por aquel entonces nació mi único hijo, Pablo, que hoy es profesor y con quien hemos hecho muchas colaboraciones, 
como por ejemplo el libro Dracmas (2005). Es interesante destacar que cuando yo me inicié como profesor, el único autor brasileño que estaba en los programas era el poeta parnasiano Olavo Bilac, y tuvo que pasar mucha agua bajo los puentes hasta que los profesores consiguiéramos que los grandes poetas y narradores brasileños se incluyeran en los programas.

CT: ¿Qué explicación tendría el contacto del estado más al Sur de Brasil, Rio Grande do Sul, con nuestras tierras en el plano del folclore?

WB: Deberíamos recordar lo que Lauro Ayestarán, el mayor musicólogo y folclorólogo uruguayo, denominaba "el país musical", área comprendida por Rio Grande do Sul, lo que era la Banda Oriental y las provincias litorales argentinas con un sustrato de folclore común, en la inmensa mayoría de los ritmos de aluvión, no autóctonos. La chamarrita viene de las Islas Açores, así como la polca, el vals, la mazurca que vienen de Europa también. Todo fue siendo adaptado, transformado, como en Rio Grande do Sul que a la habanera cubana se la transforma en la "vanera" y "vanerão", que no tienen nada que ver con el ritmo lento original. En Uruguay, fuera de los departamentos limítrofes y algunas zonas con presencia de estancieros brasileños que compraron tierras en Paysandú o Tacuarembó y generaron "islas" donde se habla portugués, portuñol o carimbão, no hay presencia del portugués, no se conoce el idioma de los "bayanos".

CT:¿Qué influencia tiene en su obra las lecturas de literatura brasileña? 
WB: Cuando profundicé en la historia de la literatura brasileña me pareció fundamental el papel de la Semana del '22 en São Paulo. Yo traduje el Cântico dos cânticos para flauta e violão de Oswald de Andrade, y $O$ escaravelho de ouro. Traduje también a Décio Pignatari y Drummond. Profundizar en los grandes creadores del modernismo brasileño me llevó a su vez a ir descubriendo los simbolistas de aquel país por un lado, a los parnasianos por otro, a la Generación del ' 45 y hasta a las generaciones actuales. Algunos íconos fueron reveladores y transformaron algunos aspectos de mi visión de la literatura, como João Guimarães Rosa, para quien las "palabras-valija” de Lewis Carroll están a la orden del día en su narrativa. De su autoría, tuve oportunidad de traducir hace añares con ayuda de Eduardo Milán para Lectores de la Banda Oriental, Com o Vaqueiro Mariano, del libro Sagarana. Como contribución en investigación, en la Facultad de Humanidades (UDELAR), hice un trabajo llamado Los Zoo y otras prosas, sobre Guimarães, y que fue editado por Ediciones de la Banda Oriental. Asimismo, traduje de Guimarães una serie de cuentos póstumos de Ave, palavra. Dentro de los narradores, también me interesa Trevisan, el heredero de la novela negra americana. En poesía, uno de los que me dio vuelta, que lo descubrí por medio de los concretistas, fue Sousândrade, quien tiene una parte de la obra post-romántica y un toque de simbolista, pero también otro material a la altura de Pound. Otro de los poetas que me tocaron muy profundamente fue Drummond, a quien tuve la oportunidad de conocer y hacerme amigo, y con quien nos carteamos. También Murilo Mendes, sobre todo porque después de un arranque con un toque surrealista, después evoluciona a los "murilogramas", caligramas de profundidad y búsqueda formal bellísima. A su vez descubrí el teatro del absurdo de Qorpo Santo, que junto con Guimarães y Sousândrade, conforman la trilogía de prosa, poesía y teatro de lo que considero más revelador de la literatura brasileña. 
CT: ¿Qué otras traducciones realizó?

$W B$ : Tuve la oportunidad de traducir una edición bilingüe de uno de los mayores poetas portugueses, Mario de Sá Carneiro, así como cuentos de Clarice Lispector, una formidable escritora, aquellos relatos infantiles preciosos. Otro poeta a quien traduje es mi amigo Affonso Romano de Sant'Anna. Es difícil muchas veces conseguir publicar traducciones del portugués, aunque tal vez hoy en día puede que haya interés en casas editoriales menos connotadas.

CT: En las traducciones que ha hecho de escritores de lengua portuguesa, ¿cuál ha sido el criterio de elección de los mismos y de sus obras? ¿El padrón de selección sigue las preferencias del lector o del académico?

WB: Del poeta, sin duda. Además, aunque siempre se rumorea que van a nombrar al autor del Tata Vizcacha académico, no me considero tal. La traducción, y aquí no soy en absoluto ingenuo después de haber leído volúmenes y volúmenes de los Cadernos da Tradução, es un misterio. Uno se plantea que hay autores intraducibles, aquellos autores que son básicamente buscadores de estructuras y escritura, como por ejemplo algunos aspectos de García Lorca. Alguna vez en clase, o en talleres en Facultad, nos planteábamos cómo traducir el "Romance Sonámbulo": "Verde que te quiero verde./Verde viento. Verdes ramas./El barco sobre la marly el caballo en la montaña.", sobre todo el "verde" famoso que le da la expresión aliterativa del comienzo. El traductor siempre está enfrentando a la traducción literal, a la recreación que planteaban los concretos, o la adaptación al idioma receptor. Son todas ellas posibilidades que ofrecen dificultades que de ninguna forma niegan el valor del original. Para mí la traducción es una 
forma de crear, porque al traducir obra ajena, uno crea. Recuerdo la afirmación de Borges sobre el folclore, cuando dice que siempre hay algo en lo que uno se apoya. Es decir, no creo que haya generación espontánea.

CT: A la hora de traducir, ¿qué estrategias se ha planteado con autores tan complejos como Guimarães Rosa, o Clarice Lispector? ¿Qué autor le ofreció mayores dificultades y desafíos a la hora de la traducción?

WB: Nunca adopté las mismas estrategias. Creo sí que no se puede traducir si uno no ha profundizado en el autor a traducir, si no le has sorbido hasta la médula. De lo contrario, quedarás en la superficie, aunque tal vez haya quien acierte. Se debe saber cómo utiliza la materia prima. Considero que hay que adaptar al autor, nunca cerrándose desde un esquema o una cosa preestablecida única. Hay muchos autores cuya traducción no cabe a no ser por medio de una recreación, como Nicolás Guillén, donde su poesía juega con elementos que en idiomas no románicos desaparecen. Personalmente, me gusta Chaucer y los Canterbury Tales, que son una mezcla de francés antiguo y el inglés que comenzaba a surgir allí, con aliteración y juego de palabras permanente de la movilización de la prosa. El que me planteó mayores dificultades fue Guimarães Rosa, sin dudas. ¡En Brasil me decían que para qué traducirlo, si muchos brasileños ni siquiera lo leían!

CT: ¿Cómo fue la experiencia de un heterónimo para la creación de las Doce canciones amorosas del juglar Xoan Zorro? ¿Cuál ha sido el papel de los heterónimos en su obra? 
WB: Cuando surge mi primer heterónimo, Pedro Agudo, mi amigo Luis Bordoli decía: "No jorobes, Bocha, esto sos vos, es un seudónimo". Una vez, yo estaba escribiendo en la máquina de escribir Underwood que heredé de mi padre, y de pronto sentí que sobre mi hombro había alguien que me estaba dictando, sentí su ajenidad. Yo tengo dos heterónimos que escribían en español como yo. Uno fue compañero mío del liceo, que pobrecito se murió en el año ' 58 y que tuvo un libro de sonetos, Amarili y otros poemas (2007), que ha sido muy premiado, lo cual me da mucha envidia. El otro fue alumno mío, nació en San Gregorio de Polanco, profesor de dibujo y se tuvo que mandar mudar para Porto Alegre, que es John Filiberto. Muchos me preguntan acerca de su nombre, y él vino del Libro del Buen Amor, de dónde saqué el nombre de Filiberto. En mi primer libro de cuentos, Moscas de Provincia (1995), cuento su historia, pero allí aparece como Juan. El último, hasta ahora, de los heterónimos es Xoan Zorro, un nombre que aparece como juglar en dos o tres juglares de los cancioneros galaico portugueses y en la literatura provenzal. Eso me sirvió pues otra de las minas a las que descendí fue la de la literatura provenzal, que me llegó por el formidable poeta argentino Enrique Banchs. Y por Ezra Pound, quien ya está en mi libro Los sueños de la razón (1968), teniendo en cuenta que una de sus predilecciones fue la literatura del dolce estilo nuovo y la literatura provenzal. Todo ello conforma mi universo. Xoan Zorro es mi heterónimo perteneciente a la literatura medieval, pero con él debí adaptar su trovar abierto de juglar.

CT: ¿Y cómo surge la idea de volver sus versos al portugués?

$W B$ : En un encuentro de poetas que hubo en Manaos, presenté las Doce canciones... en versión castellana, y el poeta Thiago de Mello se ofreció a traducirlo al portugués contemporáneo. En ese 
mismo libro aparece el otro traductor de mis poetas al portugués, Aníbal Beça, el poeta amazónico que falleció hace un año. El estudio crítico previo de los poemas, de los primeros en este país sobre la heteronimia, es de Gerardo Ciancio. Se sugiere que hay otro heterónimo mío, cuyo nombre es Julio Bordenabe, autor de una novela inédita, El poeta que vino de Tacuarembó, que una editorial perdió.

CT: ¿Cómo vive la musicalización de su obra? ¿Y cómo ha sido la labor conjunta de poeta y músico?

Siempre digo: "La música, mi madre". Mi padre fue un notable guitarrista, además de procurador. Lauro Ayestarán le grabó cuarenta temas del folclore del Norte. Como sexto hijo, la música y la canción me acompañaron siempre en mi "infancia de guerra", teniendo en cuenta que nací en 1930 y viví durante la Guerra Española, la Dictadura de Terra, y la Segunda Guerra Mundial. Actualmente, con Numa Moraes y Mario Paz, tenemos un taller de creación de canciones. He estado de los dos lados: del musicalizador de canciones, y del creador de canciones que fueron luego musicalizadas. Sigo colaborando con el "Grupo de Tacuarembó”, donde está Numa Moraes, Enrique Rodríguez Viera, mi sobrino Carlos Benavídez. La música, como ya dije, es mi madre.

Entrevista concedida a Rosario Lázaro Igoa \& Walter Carlos Costa UFSC 


\section{ANEXO}

\section{Bibliografía}

\section{Poesía}

Tata Vizcacha (1955), El poeta (1959), Los sueños de la razón: 1962-1965 (1967), Las milongas (1965), Poemas de la ciega (1968), Historias (1970), Hokusai (1975), Fontefrida (1979), Murciélagos (1981), Finisterre (1986), Fotos (1986), Tía Cloniche (1990), Lección de exorcista (1991), El molino y el agua (1993) y La luna negra y el profesor (1994), Los restos del mamut (1995), Canciones de Doña Venus (1998), El mirlo y la misa (2000), Los pies clavados (2000), Un viejo trovador (2004), Diarios del Iporá (2006). Del 2010 es la obra de su heterónimo, Doce Canciones amorosas del juglar Xoan Zorro, edición bilingüe español-portugués que realiza junto con el poeta brasileño Thiago de Mello.

\section{Ficción}

Moscas de provincia (1995), La sangre de Caín (2001).

\section{Traducciones}

ANDRADE, Oswald de. Cántico de Cánticos. Trad. Washington Benavides. Ed. bilingüe. Montevideo: Editorial Banda Oriental, 1988.

BENAVIDES, Washington. Poesía y transcreación: abordajes a la literatura brasileña. Traducciones de poemas de Carlos Drummond de Andrade, Gregório de Matos, y Oswald de Andrade. Montevideo: Biblioteca Nacional, 2007. 
GUIMARÀES ROSA, João. Con El Vaquero Mariano. Trad. Washington Benavides y Eduardo Milán. Prólogo Washington Benavides. Montevideo: Ed. de la Banda Oriental, 1979.

LISPECTOR, Clarice. "Cien años de perdón". Trad. Washington Benavides. In: El País Cultural. No 502. Montevideo, 18 de junio de 1999, p. 16.

SÁ-CARNEIRO, Mario de. 23 poemas de Mario Sá-Carneiro. Trad. Washington Benavides. Montevideo: Ed. de la Banda Oriental, 2008.

\section{Otras obras}

BENAVIDES, Washington. "Los Zoo" y otras prosas de João Guimarães Rosa: los fueros de la nostalgia en la extensa "animalia" y la inacabable flora, dispersa en su obra. Montevideo: Ed. de la Banda Oriental, Facultad de Humanidades y Ciencias, 1993.

\section{Prólogos y antologías}

ESTRÁZULAS, Enrique. Antología personal. Prólogo Washington Benavidez. Montevideo: Ed. de la Banda Oriental, 2000.

GIARDINELLI, Mempo. Luna caliente. Prólogo Washington Benavides. Montevideo: Ed. de la Banda Oriental, 2004.

MATTOS, Tomás de. Bernabé, Bernabé. Prólogo Washington Benavídes. 5a.ed. Montevideo: Ed. de la Banda Oriental, 2003. 
MURGUÍA, Julián. Cuentos de las dos orillas. Prólogo Washington Benavides. Montevideo: Ed. de la Banda Oriental, 2001.

. Antología de la poesía infantil uruguaya. Selección y prólogo Washington Benavides. Dibujos Pablo Benavidez. Montevideo: Ed. de la Banda Oriental, 1999.

ROMANO DE SANT'ANNA, Affonso. El hombre bomba. Antología. Trad. Ana Lía Torre, Washington Benavides, María Tecla, Manuel Grana, Nahuel Santana y Adán Méndez. Santiago: Editorial Chile Poesía, 2005.

RUAS, Tabajara. Netto pierde su alma. Trad. Pablo Rocca. Prólogo Washington Benavídez. Montevideo: Ed. de la Banda Oriental, UNESCO, 1997. 